OS BRUXOS DA ADMINISTRAÇÃO: COMO ENTENDER A BABEL DOS GURUS EMPRESARIAIS

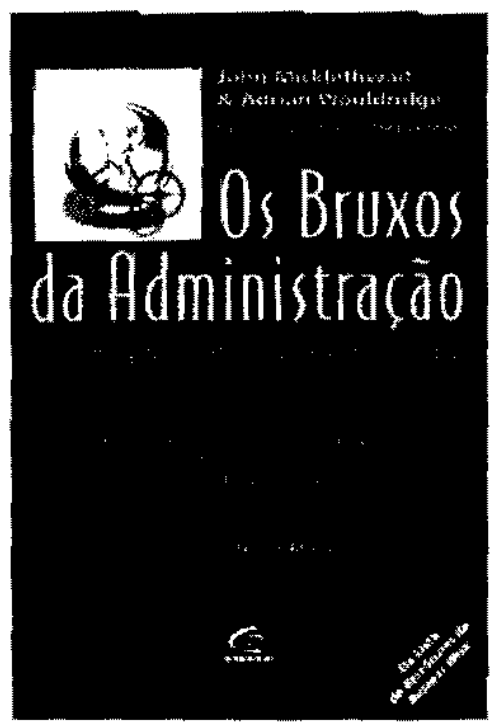

de John Mickiethwait e Adrian Wooldridge Rio de Janeiro: Campus, 1998, $327 \mathrm{p}$.

por Cecilia Whitaker Bergamini, professora do Departamento de Administraçäo Geral e Recursos Humanos da EAESPIFGV.

s dois autores, jomalistas do The Economist, comprovam, sem dúvida alguma, terem delineado um livro que se apóia em um consistente trabalho de pesquisa que permite ao leitor viajar através da maior parte das principais teorias em administraçâo, bem como conhecer os resultados alcançados depois que tais enfoques foram aplicados na prática nos mais diferentes tipos de organizaçoes. Assim sendo, o roteiro do livro nâo reside apenas em fazer uma simples meņ̧âo dos principais pensamentos dos diferentes autores muito lidos e consequientemente seguidos, praticamente o que acontece na grande maioria das obras sobre a Teoria em Administraçăo. Fssa obra muito atual vai além da simples descriç⿰彳亍o das vẩrias formas de conceber a organização através dos tempos. Os autores fazem uma critica bastante válida pela sua objetividade, o que em muito pode enriquecer a açăo da maioria dos consultores em administraçăo e dirigentes organizacionais.

A principal contribuição do livro e prevenir aqueles que o conhecem contra o uso indiscriminado dos modismos atuais em administraçăo. Depois de lê-lo certamente executivos empresariais passarão a tomar maior cuidado ao adotarem aque- les tipos de pacotes de consultoria que prometem resolver qualquer tipo de problema que as empresas que dirigem enfrentam.

De forma bastante clara, o livro ressalta que os gurus existem e atingem rápido sucesso no meio organizacional porque existem consumidores prontos a pagar pelo seu produto, permitindo assim a fama que têm. Muitos deles não recebem endosso das reconhecidas instituiçôes de ensino universitário em administraçăo. Praticamente toda a visão que oferecem $\mathrm{e}$ as soluçöes que esses iluminados doutores propôem vietam da formação recebida na "grande universidade da vida".

Avidas em suplantar dificuldades ou ameaças e desprovidas do necessário senso crítico, as empresas, em geral, aceitam como inquestionáveis as previsôes que fazem os tais gurus da administraçäo a respeito de um futuro que, na maioria das ve$z e s$, já chegou. Dentro dessa porspectiva, tais consultores con* seguem sacramentar os modismos que representa prometendo, sobretudo, oferecer às empresas para as quais trabalham aquilo que é chamado "sucesso competitivo". Quase todas essas empresax, no entanto, quando adotam inadvertidamente algum tipo de abordagem inconsistente, depois de certo tempo, começam a se mostrar enfraquecidas e passam a enfrentar problemas ainda mais perigosos que apontam para uma inapelável insolvência.

Em os Bruxos da administração, fica bastante claro que, por falta de atualização de seu conhecimento em administraçăo, muitos dos homens de negócio, prevendo um fracasso iminente da sua organizaçăo, contratam aqueles que prometem tirá-los de situaçôes difíceis e acabam por adotar sugestôes ja ultrapassadas, que nada representam senăo formas novas de justificar antigos argumentos e que são propostas como ideias revolucionárias e infalíveis em garantir a continuidade produtiva dos negocios. $O$ grande exemplo utilizado 0 das consultorias especializadas em reengenharia que surgiram no inicio da década de 90 . O enfoque oferecido pela reengenharia ế considierado pelos autores como uma especie de tentativa de adaptação da clássica teoria tayloriana à era do computador.

As cinco partes nas quais se subdivide a obra concretizam a grande maestria utilizada pelos autores em mergulhar nos temas em moda. Além de revisarem os principais aspectos da orientaçä̀ que levou as empresas a adotarem a reengenharia, o livro traz um apanhado daquilo que é chamado de "a industria da teoria da organizaçāo". A primeira parte, que engloba os capítulos $1 \mathrm{e} 2$, pode ser considerada a parte maís interessante da obra. Depois de examinar o conteúdo desses dois capítulos com enfática e imperdoável visão caricatural, a obra explora as estratégias de downsizing e da busca da qualidade total. Aqui os autores propöem de forma bem-humorada seu veredicto de que "nenhuma fómula funciona - ou pelo menos nâo de forma tão completa quanto esperam os ambiciosos e preocupados compradores. Resultado: enomes lucros para as gunus, mas confusão para seus clientes" (p. 38). Tal afirmaçä̆o parece ter inspirado a apreciação de Roosebeth $M$. Kanter quando afíma na quarta capa que o texto deve, necessariamente, ser lido antes de se comprar qualquer outro livro sobre administração e negócios.

Embora tenham formação em ciências exatas, os autores 
não se omitem em comentar o efeito que essas novidades técnicas podem ocasionar sobre o comportamento daqueles que foram atingidos por elas. A reengenharia pode, por exemplo, ser capaz de amuinar a rede informal de contatos bumanos, destruindo, assim, as proprias pessoas que ainda permanecem na empresa, sem falar naquelas que, desiludidas, deixaram a empresa, $O$ livro aponta que isso ocorre porque a reengenharia prefere agrupar pessoas de diferentes funçöes em equipes dedicadas a executar processos que abrangem varias funçoes, Assim sendo, pessoas que trabalham em marketing, finanças, projetos e pesquisas săo agrupadas em funçăo do "processo de desenvolvimento de um novo produto". Como nos demais capítulos, também neste todas as criticas dos autores sẫo fundamentadas por um consistente número de exemplos práticos.

Na segunda parte do livro, especificamente nos capítulos 3 e 4, ê apresentada uma apreciação das ideias e trabalhos desenvolvidos por Drucker \& Peters, considerados como os maiores gurus da histónia da administraçäo. Năo fica claro, no entanto, que tipo de referencial foi utilizado que pudesse permitir colocar esses dois teónicos em tanta evidência em detrimento de outros tantos que tiveram contribuiçoes tambem importantes como autores no contexto organizacional.

Austriaco de nascimento, Drucker acaba encontrando seu referencial em uma universidade americana escreve seu primeiro livro em 1939. A partir daí fica conhecido como o"inventor" da administração por objetivos. Para ele o desafio da administraçẫo é conseguir estabelecer objetivos nítidos tanto para a empresa quanto para o gerente. Para Drucker, a organização é considerada como meio para se alcançar um fim, devendo, por isso, ser estruturada de maneira a facilitar a concretização das suas proprias metas dentro de um prazo de tempo preestabelecido.

Quanto a Tom Peters, que junto com Waterman tornou-se milionário com sua primeira obra, Vencendo a crise, os autores propöem que ele trabalha com um modelo anti-racionalista de administração. Com isso aponta a inconveniencincia da administraçâo científica, que superestima a importância das recompensas financeiras na motivação daqueles que trabalham. Dentre outros efeitos perversos, o modelo racionalista promove a conformidade burocrática em detrimento da inovação.

Na terceira parte do livro, a mais densa, săo apresentadas as "grandes polêmicas". Sempre baseados em suas pesquisas, os autores apontam a tendência generalizada da teoria da administração moderna em dar muito valor aos modelos tradicionais, permanecendo obcocada pela mudança e suas consequiências. A reformulação do status quo só seră possivel quando estiver associada às virtudes da solidez burocrática e ao zelo empreendedor. Embora se possa reconhecer que, em tese, tal colocaçăo faça sentido, fica evidente que o maior problema dos seres humanos € seu conservadorismo băsico. Săo também abordadas as idéias de Senge de que as empresas de hoje devem sua vantagem competitiva à sua capacidade de aprender e continuar aprendendo.

0 capitulo 7 extremamente oportuno ao tecer críticas fatais ao planejamento estratégico, considerado como uma tentativa de gestão organizacional absolutamente ultrapassada. Os estra- tegistas, dentre outros pontos fracos, năo possuem conhecimento total daquilo que $E$ necessario às organizaçôes para que possam tomar decisões seguras. Textualmente é proposto que "no alto da lista das dificuldades está a fato de o planejomento estratégico nunca realmente levar ao pensamento estratégico. Ao contrário, fornece um ritual pedante no qual os representantes de cada departamento tentam se apoderat de qualquer recurso que esteja sendo distribuido" (p. 117). Parece que os autores ficam sem entender como, ainda nos dias de hoje, há consultores especialistas em planejamento estrategico.

Embora a obra tenha merecido o prêmio de melhor livro de Estratếgia e Liderança, é só no capítulo 8, intitulado "Tempestade na Diretoria", que o tema da liderança passa a ser abordado. Logo de início 6 ressaltado que nenhum assunto produziu mais conversa fiada do que liderança. Um dos temas altamente valorizados pelos autores diz respeito às diferenças propostas por $W$. Bennis a respeito da diferença de atitudes entre líder gerente, o que comprova ser este um dos aspectos mais pesquisados atualmente.

Ainda a respeito da liderança, o livro menciona um dos autores mais valorizados na atualidade, James McGregor Burns, que propōe a diferenciação entre Liderança Transacional e Transformacional. Os autores concluem suas apresiaçōes sobre liderança enfatizando que, mesmo com tantas incursões no campo da liderança feitas pelos diferentes teóricos, o "treinamento da liderança continua sendo um negócio impreciso e que gera desperdicio" (p. 140). Por isso, em sua grande maioria, os programas de desenvolvimento de efićácia dos líderes, embora bem conceituados, acabam quase sempre por revelar falhas. Fica claro na obra que os estudos sobre liderança sugerem formas de transformar chefes em líderes que só viriam a complicar ainda mais a vida dos antigos chefes. Passou-se a esperar que "o chefe de hoje delegue poder $e$, ao mesmo tempo, mantenha alguma forma de controle; que aproveite os talentos criativos dos seus funcionarios e tambem crie uma cultura comum dentro das empresas" (p. 142). Apesar da grande demanda por parte das organizaçồes, ainda não foi possível encontrar recursos que transformem os tradicionais chefes em líderes eficazes.

No capítulo 9, que trata do futuro do trabalho, percebe-se a tentativa de um exercício de prospecção no futuro organizacional. Diferentemente de vărios autores que prenunciam uma mudança total no mundo dos empregos, a obra adota uma visăo mais parcimoniosa, entendendo que daqui a 20 anos ainda seremos capazes de entrar em qualquer escritório e descobrir "um grapo de funcionarios grisalhos reunidos an tomo de uma cafeteina xingando seus supervisores, discutindo sobre quem esta dormindo com quem e reclamando do cafe" (p. 163). Essa proposiçẫo cautelosa mostra que mutos dos autores em administração exageraram quanto às suas previsōes sobre o fin do emprego, embora seja previsto, neste capítulo, o fim dos cargos. Nesse cenário, o emprego vitalício não se manterâ, deixando com essa perspectiva os gerentes de nivel médio sobre 0 fio de uma navalha com a perspectiva de futuras mudanças. 
A quarta parte do livro trata respectivamente nos capítulos de 10 a 12 de fenômenos como globalização, administraçăo japonesa e o novo modelo da Ásia. Embora a análise de casos reais como base das idéias dos autores seja bastante densa, aqueles que lidam com esses assuntos podem contar com uma boa fonte de informações.

Finalmente, na quinta e última parte, os temas tratados voltam a prender o interesse do leitor especialmente devido ao fato de ter sido feita uma análise muito interessante sobre as empresas caracteristicamente püblicas. Para os autores, a teoria do setor público tonou-se uma verdadeira frustraçäo. Mutitas das suas fáceis vitórias vieram das áreas privatizadas do setor público que nunca deveriam ter sido públicas. Pode-se considerar como corajosa a crítica feita a muitos consultores que, aproveitando a maré de grandes investimentos, engordam suas contas bancárias prometendo a quem os contrata resultados, muitas vezes redundantes e opostos entre si. Assim as propostas desses consultores são compradas pelas organizações porque prometem fórmulas praticamente infaliveis de contar dispêndios, melhorar serviços e estimular o moral, ao mesmo tempo em que reduzem a força de trabalho.

A obra deixa claro que a percepção de que existem diferenças tão marcantes entre o setor público e o privado leva à conclusãode que são necessárias daas teorias distintas em administração caso se queira realmente conseguir eficácia dessas instituiçôes.

Um exame crítico interessantíssimo a respeito dos modismos mais populares no setor público permite formular antigos entusiasmos a respeito do downsizing, da reengenharia e da qualidade total. Esses modismos propóem que os trabalhadores possam ser dispensáveis quanto às sugestōes do downsizing; já a qualidade total os considera extremamente valiosos e a reengenharia propõe a meihora incremental contínua. Pela simples lógica percebe-se que esses objetivos não podem conviver ao mesmo tempo numa mesma organização.

No capítulo 14, são apreciadas as idéias de Irak Adizes, Stephem Covey e Antony Robbins como os gurus que pregam a mensagem sedutora no sentido de que algurnas simples mudanças de häbitos podem eliminar bloqueios interiores, transformando o medo em forças produtivas - e isso leva à consideração de que o modelo ideal para cada um é atingir sua plenitude.

Encerrando seu trabalho, os autores oferecem uma análise crítica que toma como ponto de partida o conceito de Scott Adams, desenhista e criador do personagem Dilbert. Assim, ressaltam que "um consultor é uma pessoa que toma seu di. theiro e aborrece seus funcionaitos enquanto procura incansavelmente o melhor modo de prorragar o seu contrato de consultoria" (p. 285). Para escolher uma consultoria recomendase ser seletivo, pensando näo nos ganhos imediatos que ela possa trazer, mas nos efeitos que podem proporcionar em médio e longo prazos.

Sem dúvida o livro merece uma leitura atenta e crítica, nãa somente por parte dos executivos empresariais, mas sobretudo por parte dos consultores que trabalham com as novas e revolucionárias técnicas em administração.

\section{A MENTALIDADE ENXUTA NAS EMPRESAS: ELIMINE O DESPERDÍCIO E CRIE RIQUEZA}

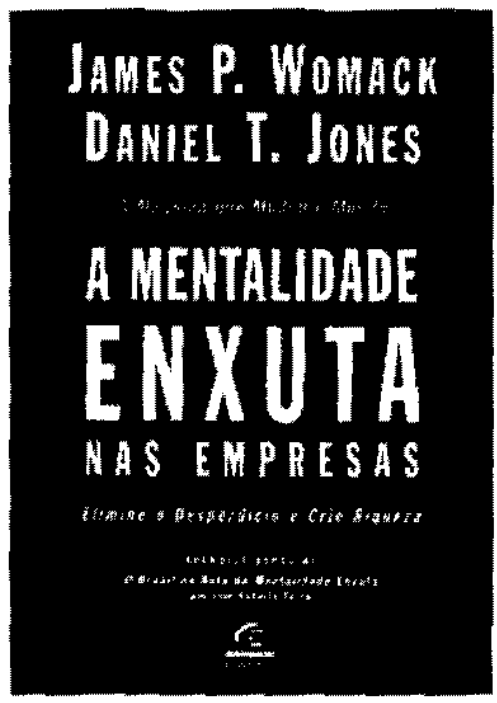

de James P. Womack e Daniel T. Jones Rio de Janeiro: Campus, $1998,428 \mathrm{p}$.

por Rodolfo Verano lozzi, aluno do Curso de Especialização para Graduados (CEAG) da EAESPIFGV.

1 economia mundial estâ globalizada ê, em consequêencia, a concorrência é mais intensa quantitativa e qualitati ₹amente. $O$ tempo é um fator que näo pode ser desperdiçado num contexto em que os velhos paradigmas empresariais são rapidamente questionados e deixados de lado, substituídos por novas maneiras de enxergar o mundo empresarial. Períodos longos de espera na linha de produção e retrabalho são expressōes proibidas num ambiente em que eliminar todo desperdício possível ê a ordem dominante.

Ainda que a palavra "globalização" esteja talvez um tanto desgastada pelo seu intenso emprego e que evitar desperdício é (ou já deveria estar sendo) uma atitude praticada nos meios produtivos, o livro A mentalidade enxuta nas empresas é essencial para lembrar aos administradores que a racionalização de recursos via redefiniçẫo de processos produtivos deve ser uma linha de ação sempre perseguida, não importando a moda administrativa do momento, 